\title{
Time trends of cancer incidence in childhood in Campania region: 25 years of observation
}

\author{
Paolo Indolfi ${ }^{1,2 *}$, Serena Picazio ${ }^{2}$, Silverio Perrotta ${ }^{1}$, Francesca Rossi ${ }^{1}$, Andrea Pession³ ${ }^{3}$ Martina Di Martino ${ }^{1}$, \\ Elvira Pota ${ }^{1}$, Daniela Di Pinto ${ }^{1}$, Cristiana Indolfi ${ }^{1}$, Roberto Rondelli ${ }^{3}$, Francesco Vetrano ${ }^{4}$ and Fiorina Casale ${ }^{1}$
}

\begin{abstract}
Background: Childhood cancer is relatively uncommon and the European age-standardized rate was 164 new case per million per year among children 0 to 14 years of age (95\% Cl 158-170). Aims of our study are to evaluate the cases of these malignant diseases observed between 0 and 15 years of age in the Campania region between 1990 and 2014, the ration between observed and expected cases by disease and province of residence. Also we studied the percentage of extra-regional migration over the time by disease and province of residence.

Methods: In this study we reported the patients with malignant disease observed in 25 years (1990-2014) based on the specialized registry, the Mod. 1.01 of the AIEOP (Association Italian Pediatric Hematology-Oncology). The size of the monitored population also allowed us to systematically examine five time trends: 1990-94: 1995-99; 2000-04; 2005-09; and 2010-14.

Results: Between 1990 and 2014 a total of 3655 malignant neoplasms were reported: Napoli province (2059 cases), Salerno province (625), Caserta province (589), Avellino province (229), and Benevento province (153). Epidemiological data suggested that about 4100 cases could be expected in Campania region during the same period. The overall ratio between observed $(O)$ and expected $(E)$ numbers of cases in the five periods considered rose gradually from 0.69 in the first period to 0.76 , then $0.82,0.91$, and 0.94 , in the other periods considered. The extra-regional migration involved 1029 cases (28.1\%), showing a reduction from $33.7 \%$ of the first period to $20.3 \%$ of the last period considered. Considering single province of residence we observed the lowest rate of migration in Napoli and Caserta province, whereas higher levels were observed in the other provinces. For all provinces, except Salerno, the extra-regional migration declined significantly over time.
\end{abstract}

Conclusions: The present findings showed an increase over time of $\mathrm{O} / \mathrm{E}$ ratio, probably due to improvement in the organization of centers and greater trust of families in local centers. It is possible to further improve the efficiency of healthcare system of Campania region and migration can be reduced with a more rational use of hospitals throughout region.

Keywords: Epidemiology, Cancer, Children

\footnotetext{
* Correspondence: paolo.indolfi@unina2.it

${ }^{1}$ Servizio di Oncologia Pediatrica, Dipartimento della Donna, del Bambino e

di Chirurgia Generale e Specialistica- Seconda Università degli Studi di

Napoli, Naples, Italy

${ }^{2}$ AlL Sezione "Valentina Picazio", Caserta, Italy

Full list of author information is available at the end of the article
} 


\section{Background}

Childhood cancer is relatively uncommon and actually the European age-standardized rate was about 164 new case per million per year among children 0 to 14 years of age (95\% CI 158-170) [1, 2]. Between 1988 and 2008 a total of 5,709 malignant neoplasms were reported in children aged 0-14 years. Incidence rates in children for all malignant cancer peaked in 1997 (211 cases/million boys and 175 cases/million girls per year), followed by a decline, non statistically significant $[1,2]$. Instead, the annual incidence rate in adolescents (15-19 years) was 269 per million (95 $\%$ CI 256-283) [3, 4]. The ranking of cancer types as defined by the ICCC-3 (International Classification for Childhood Cancer) classification shows that leukemias are the most frequent neoplasms (33\% of all malignant cancers), followed by lymphomas (16 \%), malignant tumours of Central Nervous System (CNS) (13\%), which increase to $18 \%$ when including non-malignant tumours), followed by neoplasms of the peripheral nervous system (8\%), and the soft tissue cancers $(7 \%)$. The remaining neoplasms, more rare, account for no more than $5 \%$ each and $23 \%$ altogether $[5,6]$. Aims of our study are to evaluate the incidence of these malignant diseases observed between 0 and 15 years of age in the Campania region, the ration between observed and expected cases by disease and province of residence. Also we studied the percentage of extra-regional migration over the time by disease and province of residence. A minor objective was to evaluate an eventually increase of incidence of cancer in Napoli and Caserta provinces, called "Ground of fires", from involuntuary exposure to environmental pollutants. However, it is worth remembering that a correlation between pollution and cancer requires several types of evidence and a systematic approach following well-defined criteria and methods that make it a specialized activity.

\section{Methods}

For this report we selected all cancer cases diagnosed in the $0-15$ years age group. The age specific rates were computed dividing the number of newly diagnosed cases in a period in this group of age of population by the corresponding population in the same period. The rates defines the mean number of diagnoses in one year and is referred to 1,000,000 subjects of the specific age group. The European age-standardized rate was 164 new cases per million children per year (95\% CI 158-170) [5] In this study we reported the number of patients with malignant disease diagnosed before their 15th birthday and observed in 25 years (1990-2014), based on the specialized registry, the Mod. 1.01 of the AIEOP (Association Italian Pediatric Hematology-Oncology). This centralized archive, called Model (Mod.) 1.01, has been in use since 01.01.1989 and records essential standardized information on all cases of childhood cancer for ages 0-19 years, diagnosed and/or treated in the AIEOP centers. For this reason we started our analysis since 1990 . We recognize the limits of the Mod. 1.01 as a potential cancer registry. An study was estimated for the period 1989-1998, as a total and by tumour type, comparing the recruitment $v s$ the expected numbers based on the incidence rates measured by the Childhood Cancer Registry of Piedmont. Results showed good correspondence [7]. Actually the AIEOP database to include in Italy about the $90 \%$ of children aged 0-15 years affected by cancer. The size of the monitored population also allowed us to systematically examine five time trends: 1990-94; 1995-99; 2000-04; 2005-09; and 2010-14. The evaluation of expected cases is considered related to the population in a province and the number of children residents in the same province. In detail, the global number of people in Campania region is of 5,790,929 and of 1,014,796 between 0-15 years old. Corresponding global population and $0-15$ years people, were respectively for Napoli 3,086,622 and 572,335; Salerno 1,090,934 and 173,335; Caserta 886,758 and 160,277; Avellino 437,414 and 65,566; and Benevento 289,201 and 43,355 residents. (Specialized Registry for childhood Campania Region). Based on these numbers of

Table 1 Characteristics and numbers of children (0-15 years old) diagnosed with cancer in Campania Region between 1990 and 2014, registered in the AIEOP Mod. 1.01

\begin{tabular}{ll}
\hline Diagnostic period & No (\%) of patients \\
\hline 1990-1994 & $611(16.7)$ \\
$1995-1999$ & $673(18.4)$ \\
$2000-2004$ & $726(19.8)$ \\
$2005-2009$ & $806(22.0)$ \\
$2010-2014$ & $839(22.9)$ \\
Sex & \\
Male & $2036(55.7)$ \\
Female & $1619(44.2)$ \\
Type of Disease & \\
Acute lymphoblastic/hybrid Leukemia & $1036(28.3)$ \\
Acute non lymphoblastic Leukemia & $220(6.0)$ \\
Chronic Myeloid Leukemia & $24(0.6)$ \\
Non Hodgkin Lymphoma & $281(7.6)$ \\
Hodgkin Lymphoma & $189(5.1)$ \\
CNS Tumours & $500(13.6)$ \\
No CNS Tumours & $1405(38.4)$ \\
Province of residence & \\
Napoli & $2059(56.3)$ \\
Salerno & $625(17.0)$ \\
Caserta & $589(16.1)$ \\
Avellino & $229(6.2)$ \\
\hline
\end{tabular}


Table 2 Observed malignant cancer cases by disease and period of observation (\%)

\begin{tabular}{|c|c|c|c|c|c|}
\hline Disease & 1990-1994 & 1995-1999 & 2000-2004 & 2005-2009 & 2010-2014 \\
\hline$\overline{A L L}$ & $210(20.5)$ & $193(18.8)$ & $205(20.0)$ & $199(19.4)$ & $217(21.1)$ \\
\hline LA hybrid/undiff. & $6(50.0)$ & $4(33.3)$ & $1(8.3)$ & $1(8.3)$ & 0 \\
\hline ANLL & $39(17.7)$ & $42(19.0)$ & $40(18.1)$ & $50(22.7)$ & $49(22.2)$ \\
\hline$M C L$ & $5(20.8)$ & $3(12.5)$ & $3(12.5)$ & $4(16.6)$ & $9(37.5)$ \\
\hline $\mathrm{NHL}$ & $52(18.5)$ & $63(22.4)$ & $59(20.9)$ & $61(21.7)$ & $46(16.3)$ \\
\hline $\mathrm{HL}$ & $16(8.4)$ & $35(18.5)$ & $35(18.5)$ & $41(21.6)$ & $62(32.8)$ \\
\hline Neuroblastoma & 75 (21.9) & $58(16.9)$ & $67(19.5)$ & $72(21)$ & $70(20.4)$ \\
\hline CNS Tumour & $31(6.2)$ & 78 (15.6) & 118 (23.6) & $122(24.4)$ & $151(30.5)$ \\
\hline Kidney Tumour & $44(21.7)$ & $45(22.2)$ & $29(14.3)$ & $39(19.3)$ & $45(22.2)$ \\
\hline Soft tissue sarcoma & $31(14.6)$ & $44(20.7)$ & $45(21.2)$ & $56(26.4)$ & $36(16.9)$ \\
\hline Histiocytosis & $25(14.8)$ & $27(16.0)$ & 33 (19.6) & $47(27.9)$ & $36(21.4)$ \\
\hline GCT & $15(14.0)$ & $18(16.8)$ & $12(11.2)$ & $29(27.1)$ & $33(30.8)$ \\
\hline S. Ewing/PNET & $14(12.8)$ & $20(18.3)$ & $22(20.1)$ & $22(20.1)$ & $31(28.4)$ \\
\hline Retinoblastoma & $16(20.7)$ & $9(11.6)$ & $22(28.5)$ & $20(25.9)$ & $10(12.9)$ \\
\hline Bone Tumour & $16(25.3)$ & $12(19.0)$ & $8(12.6)$ & $14(22.2)$ & $13(20.6)$ \\
\hline Liver Tumour & $6(13.3)$ & $12(26.6)$ & $9(20.0)$ & $8(17.7)$ & $10(22.2)$ \\
\hline Nasofaryngeal carcinoma & $3(33.3)$ & $1(11.1)$ & $2(22.2)$ & $2(22.2)$ & $1(11.1)$ \\
\hline Adrenocortical carcinoma & $3(27.2)$ & $2(18.1)$ & $3(27.2)$ & 0 & $3(27.2)$ \\
\hline Other Tumours & $4(6.6)$ & $7(11.6)$ & $13(21.6)$ & 19 (31.6) & $17(28.3)$ \\
\hline Total & $611(16.7)$ & $673(18.4)$ & $726(19.8)$ & $806(22)$ & 839 (22.9) \\
\hline
\end{tabular}

ALL acute lymphoblastic leukemia, ANLL acute non lymphoblastic leukemia, $M C L$ myeloid chronic leukemia, NHL non hodgkin lymphoma, $H L$ hodgkin lymphoma, CNS central nervous system, GCT germ cell tumour, PNET peripheral neuroectodermal tumor

children the expected cases of malignant neoplasm per year were for province of Napoli (93 cases); Salerno (28 cases); Caserta (26 cases); Avellino (10 cases); and Benevento (7 cases). The ranking of cancer types as defined by ICCC-3 show per year solid cancer non CNS as the most frequent neoplasms (61 cases), followed by leukemias (52 cases), CNS tumours (41 cases), and Hodgkin/non Hodgkin lymphomas (23 cases) [5]. We have calculated the number of observed cases $(\mathrm{O})$ in the long time in Campania region and then we have analyzed the ratio between observed and expected (E) numbers of cases. The Breslow-ay test was used to assess $\mathrm{O} / \mathrm{E}$ trends by diagnostic period. The aim was to check an eventually better $\mathrm{O} / \mathrm{E}$ ratio over time to demonstrate that more cases have been treated at local centers. A secondary aim was to verify an eventually surplus of malignant cancer cases observed in the specific 5-year time and/or in the several provinces of Campania region. Finally, we have evaluated the extra-region migration as the number of the children affected by malignant neoplasm diagnosed and/or treated in other regions (or Countries) from where they live.

\section{Results}

Global analysis

During the study period 3655 cancer patients aged 0-15 years old were registered in the AIEOP database, 2036 males $(55.7 \%)$ and 1619 females (44.2\%). Epidemiological data suggest that about 4.100 cases in Campania Region and 37,000 cases in Italy could be expected during the same period. Table 1 shows all cases registered by diagnosis and

Table 3 Ratio between observed and expected cases by type of cancer and period of observation (\%)

\begin{tabular}{|c|c|c|c|c|c|c|c|}
\hline \multirow[t]{2}{*}{ Disease } & \multirow[b]{2}{*}{ E } & \multicolumn{2}{|c|}{ 1990-1994 } & \multirow{2}{*}{$\begin{array}{l}\text { 1995-1999 } \\
\text { O/E }\end{array}$} & \multirow{2}{*}{$\begin{array}{l}\text { 2000-2004 } \\
\text { O/E }\end{array}$} & \multirow{2}{*}{$\begin{array}{l}\text { 2005-2009 } \\
\text { O/E }\end{array}$} & \multirow{2}{*}{$\begin{array}{l}2010-2014 \\
\text { O/E }\end{array}$} \\
\hline & & $\bar{O}$ & $\mathrm{O} / \mathrm{E}$ & & & & \\
\hline Leukemias & 260 & 260 & 1.0 & 0.93 & 0.95 & 0.97 & 1.0 \\
\hline Limphomas & 115 & 68 & 0.59 & 0.85 & 0.81 & 0.88 & 0.93 \\
\hline CNS tumours & 205 & 31 & 0.15 & 0.38 & 0.57 & 0.59 & $0.73^{*}$ \\
\hline Solid tumours (no CNS) & 305 & 252 & 0.82 & 0.83 & 0.86 & 1.0 & 1.0 \\
\hline
\end{tabular}

CNS central nervous system, $E$ expected cases/five years, $O$ observed cases/five years 
Table 4 Ration between observed and expected cases by province of residence at diagnosis and period of observation (\%)

\begin{tabular}{|c|c|c|c|c|c|c|c|}
\hline \multirow{2}{*}{$\begin{array}{l}\text { Province } \\
\text { of } \\
\text { residence }\end{array}$} & \multirow[b]{2}{*}{$E / 5$ years } & \multicolumn{2}{|c|}{ 1990-1994 } & \multirow{2}{*}{$\begin{array}{l}\text { 1995-1999 } \\
\text { O/E }\end{array}$} & \multirow{2}{*}{$\begin{array}{l}\text { 2000-2004 } \\
\text { O/E }\end{array}$} & \multirow{2}{*}{$\begin{array}{l}\text { 2005-2009 } \\
\text { O/E }\end{array}$} & \multirow{2}{*}{$\begin{array}{l}\text { 2010-2014 } \\
\text { O/E }\end{array}$} \\
\hline & & $\mathrm{O}$ & $\mathrm{O} / \mathrm{E}$ & & & & \\
\hline Napoli & 465 & 344 & 0.73 & 0.82 & 0.90 & 0.98 & $0.96^{*}$ \\
\hline Caserta & 130 & 101 & 0.77 & 0.71 & 0.83 & 0.99 & $1.2^{*}$ \\
\hline Salerno & 140 & 97 & 0.69 & 0.84 & 0.85 & 0.94 & 1.1 \\
\hline Avellino & 50 & 40 & 0.80 & 1.0 & 0.80 & 1.0 & 0.90 \\
\hline Benevento & 35 & 29 & 0.82 & 0.74 & 1.0 & 0.94 & 0.77 \\
\hline
\end{tabular}

$E$ expected cases/five years, $O$ observed cases/five years

${ }^{*} \mathrm{p}<0.05$ for trend across diagnostic periods

province of residence in the five diagnostic period considered. Table 2 shows in detail all cases observed by type of disease in the five diagnostic period considered.

\section{O/E ratio cases by type of cancer and period of observation}

Related to the European age-standardized rate of about 164 new case per million per year among children 0-15 years and the ranking of cancer type as defined by the ICCC-3 we expected in Campania Region every five years time period about 260 cases of Leukemias; 115 cases of Lymphomas; 305 cases of Solid tumours (No CNS); and 205 cases of CNS tumours. Table 3 shows all cases observed and the $\mathrm{O} / \mathrm{E}$ ratios in the five diagnostic period considered. The $\mathrm{O} / \mathrm{E}$ ratio rose gradually from the first 5-year time to the last period for Lymphomas, CNS tumours, and Solid tumours (No CNS); the improvement was statistically significant for CNS tumours. The O/E ratio was particularly high for Leukemias.

\section{O/E ratio cases by province of residence at diagnosis and period of observation}

Based on the number of children living in Campania region the expected cases of malignant neoplasm every five years of observation were 465 for province of Napoli, 140 for Salerno, 130 for Caserta, 50 for Avellino, and 35 for Benevento. Table 4 shows the $\mathrm{O} / \mathrm{E}$ ratios in the five diagnostic periods considered. The overall $\mathrm{O} / \mathrm{E}$ ratio rose gradually from the first period to the last period considered, with the exception of Benevento province. This improvement was statistically significant for Napoli and Caserta provinces, as trend across diagnostic periods. In the Caserta and Salerno provinces the O/E ratio was particularly high $(>1)$ in the last 5-year time.

\section{Extra-regional migration by period of observation and type of disease}

Analyzing the 3655 cases who were diagnosed in the period 1990-2014, extra-regional migration involved 1029 (28.1 \%) cases. Table 5 shows the global extraregional migration for all cases, by disease. Table 6 shows in detail the variation in the five diagnostic periods considered of all malignat neoplasms observed. The analysis over time proves a progressive improvement for more frequent pediatric neoplasms. In detail, we observed for acute/hybrid lymphoblastic leukemias a progressive reduction of extra-regional migration from $18.5 \%$ of the first period examined to $10.1 \%$ of the last 5 -year time (2010-2014), as for acute non lymphoblastic leukemia from $38.4 \%$ to $12.2 \%$, Also, we observed a very good reduction of migration over time for lymphomas, neuroblastoma and kidney cancer, with a reduction from

Table 5 Extra-regional migration of the 3655 patients studied by disease and province of residence

\begin{tabular}{ll}
\hline Disease & No patients/total (\%) \\
\hline Acute lymphoblastic/hybrid Leukemia & $143 / 1036(13.8)$ \\
Acute non lymphoblastic Leukemia & $37 / 220(16.8)$ \\
Chronic Myeloid Leukemia & $3 / 24(12.5)$ \\
Non Hodgkin Lymphoma & $73 / 281(25.9)$ \\
Hodgkin Lymphoma & $47 / 189(24.8)$ \\
Neuroblastoma & $93 / 342(28.9)$ \\
CNS Tumours & $251 / 500(50.2)$ \\
Kidney Tumours & $44 / 202(21.7)$ \\
Soft Tissue Sarcoma & $70 / 212(33.0)$ \\
Histiocytosis & $40 / 168(23.8)$ \\
Germinal Cell Tumours & $24 / 107(22.4)$ \\
S. Ewing/PNET & $57 / 109(52.2)$ \\
Retinoblastoma & $50 / 77(64.9)$ \\
Bone Tumours & $42 / 63(66.6)$ \\
Liver Tumours & $22 / 45(48.8)$ \\
Other Tumours & $27 / 60(45.0)$ \\
Total & $1029 / 3655(28.1)$ \\
Province of residence &
\end{tabular}

CNS central nervous system, PNET peripheral neuroectodermal tumor 
Table 6 Extra-regional migration by period of observation and type of disease (\%)

\begin{tabular}{|c|c|c|c|c|c|}
\hline Disease & 1990-1994 & 1995-1999 & $2000-2004$ & 2005-2009 & 2010-2014 \\
\hline$\overline{A L L}$ & $40(18.5)$ & $29(15)$ & $29(14.7)$ & $23(11.1)$ & $22(10.1)$ \\
\hline ANLL & $15(38.4)$ & $7(16.6)$ & $3(7.5)$ & $7(14)$ & $6(12.2)$ \\
\hline $\mathrm{MCL}$ & $1(20.0)$ & $1(33.3)$ & $1(33.3)$ & 0 & 0 \\
\hline NHL & $19(36.5)$ & $22(34.9)$ & $18(30.5)$ & 12 (19.6) & $2(4.3)$ \\
\hline $\mathrm{HL}$ & $5(31.2)$ & $8(22.8)$ & $14(40.0)$ & $9(21.9)$ & $11(17.7)$ \\
\hline Neuroblastoma & $32(42.6)$ & $22(37.9)$ & $17(25.3)$ & $19(26.3)$ & $9(12.8)$ \\
\hline CNS Tumour & 25 (80.6) & $40(51.2)$ & $67(56.7)$ & $66(54)$ & $53(35.0)$ \\
\hline Kidney Tumour & $14(31.8)$ & $10(22.2)$ & $7(24.1)$ & $7(17.9)$ & $6(13.3)$ \\
\hline Soft tissue sarcoma & $12(38.7)$ & $10(22.7)$ & $20(44.4)$ & $20(35.7)$ & $8(22.2)$ \\
\hline Histiocytosis & $4(16.0)$ & $7(25.9)$ & $10(30.3)$ & $10(21.2)$ & $9(25.0)$ \\
\hline GCT & $4(26.6)$ & $3(16.6)$ & $4(33.3)$ & $7(24.1)$ & $6(18.1)$ \\
\hline S. Ewing/PNET & $9(64.2)$ & $14(70.0)$ & $8(36.3)$ & $9(40.9)$ & $17(54.8)$ \\
\hline Retinoblastoma & $2(12.5)$ & $3(33.3)$ & $17(77.2)$ & $18(90)$ & $10(100)$ \\
\hline Bone Tumour & $15(93.7)$ & $11(91.6)$ & $6(75.0)$ & $7(50)$ & $3(23.0)$ \\
\hline Liver Tumour & $4(66.6)$ & $7(58.3)$ & $4(44.4)$ & $4(50)$ & $3(30.0)$ \\
\hline Other Tumours & $5(50.0)$ & $6(60.0)$ & $4(22,2)$ & $5(23.8)$ & $7(33.3)$ \\
\hline Total & 206/611 (33.7) & 200/673 (29.7) & $229 / 726$ (31.5) & 223/806 (27.6) & $171 / 839(20.3)$ \\
\hline
\end{tabular}

ALL acute lymphoblastic leukemia, $A N L L$ acute non lymphoblastic leukemia, $M C L$ myeloid chronic leukemia, $N H L$ non hodgkin lymphoma, $H L$ hodgkin lymphoma, CNS central nervous system, GCT germ cell tumour, PNET peripheral neuroectodermal tumor

$36.5 \%, 42.6 \%$, and $31.8 \%$ for a first 5 -year time to $17.7 \%$, $12.8 \%$, and $13.3 \%$, respectively. A minor improvement over time was registered for a soft tissue sarcomas with a percentage of reduction from $38.7 \%$ to $22.2 \%$ of the 2010-2014 period. Actually, non-satisfactory results were related to CNS tumors and Ewing/PNET sarcomas with a percentage reduction from $80.6 \%$ and $64.2 \%$ to $35 \%$ and $54.8 \%$, respectively. Different is the problem related to the retinoblastoma, probably due to the more specific diagnostic and therapeutic approach. In fact, we observed a progressive extra-regional migration over time from a 12.5 $\%$ of the period 1990-1994 to $100 \%$ of the $2010-2014$ (Table 6).

\section{Extra-regional migration by province of residence}

Table 5 shows the extra-regional migration of the patients by province of residence. In Table 7 was evident the reduction of migration over time in the five provinces of Campania region even if with different results.
Better results were registered for Napoli and Caserta whereas in the last 5-year time considered in the other three provinces more cases opted for the diagnosis and/ or treatment in centers of a different region: Salerno (36.7\%); Avellino (26.6\%), and Benevento (25.9\%).

\section{Discussion}

The present findings update descriptive cancer epidemiology in children ( $0-15$ years) in Campania in the period 1990-2014 (25 years of observation) based on data provided by specialized clinical Mod.1.01 from AIEOP centers. The cases of cancer expected in Campania in this period, calculated using the last AIRTUM's site-specific incidence rates by age group (0-15 years), were about 4,100 cases $(11.5 \%)$, of which $29.7 \%$ were leukemias, $14.5 \%$ were lymphomas, $20.4 \%$ were CNS tumours, and $35.4 \%$ were solid neoplasms non CNS. These percentages bring about a number of expected cases per year of 51 cases of leukemia, 25 cases of lymphoma, 35 cases of

Table 7 Extra-regional migration by province of residence at diagnosis and period of observation of the 1029 patients examined (\%)

\begin{tabular}{|c|c|c|c|c|c|}
\hline Province of residence & 1990-1994 & 1995-1999 & 2000-2004 & $2005-2009$ & 2010-2014 \\
\hline Napoli & $85(24.7)$ & 72 (18.7) & $92(21.9)$ & $82(17.8)$ & $61(13.5)$ \\
\hline Caserta & 32 (31.6) & 31 (33.3) & $40(37.0)$ & $39(30.2)$ & $33(20.8)$ \\
\hline Salerno & $44(45.3)$ & $53(44.9)$ & $56(46.6)$ & 55 (41.6) & $58(36.7)$ \\
\hline Avellino & $21(52.5)$ & $23(45)$ & $19(47.5)$ & $29(54.7)$ & $12(26.6)$ \\
\hline Benevento & $17(58.6)$ & $12(46.1)$ & $18(47.3)$ & $14(42.4)$ & $7(25.9)$ \\
\hline
\end{tabular}


CNS tumours, and 61 cases of solid cancer non CNS. The present study shows that $\mathrm{O} / \mathrm{E}$ ratio for leukemias and solid neoplasms non CNS was high since 1990 to demonstrate the efficacy of AIEOP organization and Mod. 1.01 for these diseases. Instead, the improvement of observation for lymphomas was more gradual over time and a increase of O/E ratio was observed from 0.59 in the period 1990 1994 to the most cases have recently been treated at local centers AIEOP. Recently, better O/E ratio was evident for CNS tumours with a two thirds cured in local centers, respect to the 0.15-0.38 O/E ratio observed in the 19902000 period. These results probably are due to substantial improvements in non-invasive diagnostic techniques but also to better collaboration between pediatric and neurosurgery oncologists. These data were calculated using the Italian Network of Cancer Registries (AIRTUM) that includes 32 general cancer registries and five specialized which two dedicated to childhood ( $0-14$ years), including about 4,000,000 of children. According to the province of residence in Campania in our study the overall $\mathrm{O} / \mathrm{E}$ ratio rose gradually from the first time to last 5-year time and in 2010-2014 this ratio was particularly high (>1) for cancer observed in province of Caserta and Salerno. Conversely, the lowest $\mathrm{O} / \mathrm{E}$ ratios were seen in province of Benevento. The analysis of extra-regional migration shows a progressive improvement of reduction over time, particularly for emo-lymphoproliferative diseases, neuroblastoma, and kidney cancer (under $20 \%$ in the last period). Actually, there is still a relevant elective migration (more of $30 \%$ ) for CNS tumours, Ewing/PNET sarcomas, liver and rare tumours. This situation is motivated by organizational shortcomings which have created a historically rooted distrust toward health centers in their home region. This is particularly true for retinoblastoma were the rarity of neoplasm and specific local diagnostic and therapeutic approach makes migration toward another region obligatory. Our data are according to AIRTUM registry where the extra-regional migration of Campania involved $31.1 \%$ of cases in the five-year period 2001-2005 vs $35.5 \%$ of our patients and $25.6 \%$ of cases during the next five years (2006-2010) vs $27.6 \%$ of our observation. Better results (20.3\%) were registered in our region in the last period considered $[5,6]$. The evaluation of migration by province of residence describes a progressive reduction over time in the different provinces even if the better results were registered for Napoli and Caserta. Minor results have been registered for Benevento and Avellino, while the lowest rate of reduction was observed in Salerno with a decrease of $9 \%$ at last period respect to the percentage of the first period 1990-1994. In a 2005 Censis study on the reason behind patient migration, two third of respondents declared their primary reason was search for quality, the desire to make use of higher quality hospital facilities and medical personnel [5]. These reasons explain the importance to make a Network Campania of Pediatric Oncology (NETCOP) in order to do more efficacy the collaboration between the regional centers of pediatric oncology (Hub centers) and pediatric hospitals present in the five province of Campania region (Spoke centers). In the next future other problem is the recruitment of immigrant children that underwent a progressive, steady increase over the years, growing from 30 cases $(2 \%$ of the total number) in 1999 to 130 cases ( $8 \%$ of the total number) in 2008 [8-10]. Actually, AIEOP centers in Campania treated $2.4 \%$ of immigrant children [5].

\section{Conclusions}

The present findings update descriptive cancer epidemiology in children (0-15 years old) in Campania based on data provided by specialized clinical Mod.1.01 from AIEOP centers and showed an increase over time of $\mathrm{O} / \mathrm{E}$ ratio, probably due to improvement in the organization of centers and greater trust of families in local centers. Findings derived from this analysis suggest that it is possible to further improve the efficiency of healthcare system of Campania region and migration, problem actually still relevant for the specific cancers that can be reduced with a more rational use of hospitals throughout region.

\section{Acknowledgments}

We would like to thank Dr. David Pagnini and Dr. Ciro Ruggiero for supporting the work.

\section{Funding}

This study was supported by a non-restricted grant by Sezione AlL "Valentina Picazio"-Caserta. The All had no role in the design and conduct of the study; collection, management, analysis, and interpretation of the data; preparation, review, or approval of the manuscript; and decision to submit the manuscript for publication.

\section{Authors' contributions}

$\mathrm{PI}, \mathrm{SP}$, participated in study conception and design, performed the final statistical analyses, contributed to the interpretation of data and drafted the paper. SP, FR, FC, participated in study conception and design, contributed to the interpretation of data and critically revised the manuscript for its intellectual content. MDM, EP, DDP, Cl, FV, AP, RR critically revised the manuscript for its intellectual content. All authors read and approved the final manuscript.

\section{Competing interests}

The authors declare that they have no competing interests.

\section{Author details}

'Servizio di Oncologia Pediatrica, Dipartimento della Donna, del Bambino e di Chirurgia Generale e Specialistica- Seconda Università degli Studi di Napoli, Naples, Italy. ${ }^{2}$ All Sezione "Valentina Picazio", Caserta, Italy. ${ }^{3}$ Unità di Oncologia ed Ematologia Pediatrica "Lalla Seràgnoli", Università di Bologna, Bologna, Italy. ${ }^{4}$ Responsabile Registro Tumori Infantili Regione Campania, Naples, Italy.

Received: 28 June 2016 Accepted: 10 August 2016

Published online: 06 September 2016

References

1. Pritchard-Jones K, Kaatsch P, Steliarova-Foucher E, et al. Cancer in children and adolescents in Europe: developments over 20 years and future challenges. Eur J Cancer. 2006:42:2183-90. 
2. Kaatsch P. Epidemiology of childhood cancer. Cancer Treat Rev. 2010;36(4): 277-85.

3. Gatta G, Zigon G, Capocaccia R, EUROCARE Working Group, et al. Survival of European children and young adults with cancer diagnosed 1995-2002. Eur J Cancer. 2009:45:992-1005.

4. Ferrari $A$, Dama $E$, Pession $A$, et al. Adolescents with cancer in Italy: entry into the national cooperative pediatric oncology group AIEOP trials. Eur J Cancer. 2009;45:328-34.

5. AIRTUM Working Group CCM AIEOP Working Group. Italian Cancer Report 2012: Cancer in children and adolescents. Epidemiol Prev. 2013;37(1 Suppl I):1-296.

6. Pession A, Rondelli R. I tumori dei bambini e adolescenti in Italia. Prospettive in Pediatria. 2013;43(172):226-32.

7. Pession A, Dama E, Rondelli R, et al. Survival of children with cancer in Italy,1989-1998. A report from the hospital based registry of the Italian association of pediatric Hematology and Oncology (AIEOP). Eur J Cancer. 2008;44(9):1282-9.

8. Ferrari A, Rondelli R, Pession A, et al. Adolescents with cancer in Italy: improving access to national cooperative pediatric oncology group (AIEOP) centers. Pediatr Blood Cancer. 2016;63:1116-9.

9. Pession A, Rondelli R. The italian hospital-based registry of paediatric cancer run by AIEOP. Epidemiol Prev. 2008;32(2):102-5.

10. Rondelli R, Dini G, De Rosa M, et al. Foreign children with cancer in Italy. Ital J Pediatr. 2011;37:44

\section{Submit your next manuscript to BioMed Central} and we will help you at every step:

- We accept pre-submission inquiries

- Our selector tool helps you to find the most relevant journal

- We provide round the clock customer support

- Convenient online submission

- Thorough peer review

- Inclusion in PubMed and all major indexing services

- Maximum visibility for your research

Submit your manuscript at www.biomedcentral.com/submit 